\title{
Key Components of Learning Environments in Creating a Positive Flipped Classroom Course Experience
}

\author{
Mareena Hyypiä 1 \\ University of Eastern Finland \\ Joensuu, Finland \\ https://orcid.org/0000-0003-3767-5573 \\ Erkko Sointu 2,1 \\ University of Eastern Finland \\ Joensuu, Finland \\ https://orcid.org/0000-0003-4001-7264 \\ Laura Hirsto \\ University of Helsinki/University of Eastern Finland \\ Helsinki/Joensuu, Finland \\ https://orcid.org/0000-0002-8963-3036 \\ Teemu Valtonen \\ University of Eastern Finland \\ Joensuu, Finland \\ https://orcid.org/0000-0002-1803-9865
}

\begin{abstract}
This study focused on higher education and learning environments within the context of the flipped classroom (FC) approach. Using a mixed-methods approach, this study aimed to identify how the various components of the learning environment affected higher education students' $(N=414)$ positive learning experience in FC courses. The results highlighted that students with different levels of satisfaction with the FC courses differed significantly in terms of their perspectives regarding the guidance received in the FC study method, teaching aimed at understanding, teachers' pedagogical content knowledge, the creation and maintenance of a safe course atmosphere for learning, support from peers and teachers, and the use of technology in learning. The findings offer valuable insights into what creates a positive learning experience in a university course incorporating the FC
\end{abstract}

${ }^{1}$ This paper has two first authors with equal contribution ${ }^{2}$ Corresponding author: Erkko Sointu, erkko.sointu@uef.fi 
approach and how this experience can be supported by both the teacher's personal actions and the institutional training.

Keywords: flipped classroom, higher education, learning environment, learning experience, mixed-methods research

\section{Introduction}

Universities today need to be able to meet changing societal expectations; students need to be prepared to function in the rapidly developing workplace. The essential skills have been described by various stakeholders, under various headings, but they are often denominated the $21^{\text {st }}$ century skills (e.g., Voogt \& Pareja Roblin, 2012). Typically, these descriptions place a strong emphasis on learning skills, collaboration, creativity, critical thinking, ability to cope with new situations, skills for lifelong learning, and the skills and readiness to use information and communication technology (ICT). Still, in addition to these more generic skills, diverse content expertise is often considered highly important. These expectations call for the development of higher education teaching and learning practices that consider the effects of diverse learning environments on teaching and learning.

Higher education itself can be seen as a changing and evolving entity. In the 1990s, Barr and Tagg (1995) described the changes in higher education teaching and learning practices as moving from the instruction paradigm toward the learning paradigm, emphasizing student-centered teaching and learning methods. Similarly, Harasim (1996) described the changes as a shift from broadcasting knowledge to knowledge construction. According to Harasim (1996), higher education based solely on lecturing is inadequate; more attention needs to be given to students and the ways in which they build knowledge and skills. Many pedagogical models support the active use of student-centered teaching and learning practices, such as problem-based learning, inquiry-based learning, and the flipped classroom (FC) approach, which is discussed in this article. The key to all models and approaches is to provide teaching staff with tools, that is, more concrete models for developing their teaching in a more student-centered direction.

Various opportunities offered by ICT and related pedagogical solutions have also contributed to the changing field of higher education pedagogy. The integration of ICT into teaching has been guided by many scholars. Wang (2008) emphasizes the complementary nature of pedagogy, social interaction, and technology. The annual Horizon reports provide insights into the future of higher education from the perspectives of technology and pedagogy (Freeman, Adams Becker, Cummins, Davis, \& Hall Giesinger, 2017). Currently, future visions focus strongly on solutions based on artificial intelligence and student data, such as learning analytics and more personalized learning opportunities. The role of ICT also emerges from more practical premises: Ossiannilsson (2018) highlights the role of technology as a way to provide more flexible and accessible higher education. This theme represents an important feature of today's universities, as instead of catering to the traditional full-time student, the 
field is becoming more heterogeneous, with fewer and fewer on-site opportunities to study.

This study explored the challenges and possibilities discussed above through practical experimentation. The research context was an extensive development project within a Finnish university, where the aim has been to develop the academic learning environment by introducing more student-centered teaching and learning methods and improving the use of ICT as part of teaching and learning practices. A key element in this development project has been implementing the FC approach as a way to change the teaching and learning practices. This study focuses on investigating students' experiences of courses taught using the FC approach. As O'Flaherty, Phillips, Karanicolas, Snelling, and Winning (2015) presented in their extensive literature review, mixed results have been found in students' perception of and satisfaction with FC (see also, e.g., Critz \& Knight, 2013; Missildine, Fountain, Summers, \& Gosselin, 2013; Yeung \& O'Malley, 2014), with only a small number of mentions of specific elements that promote positive views of FC (Mason, Shuman, \& Cook, 2013; Prober \& Khan, 2013). Thus, our aim is to investigate students' satisfaction with the FC approach in terms of their perspectives regarding the key components of learning environments, using a mixed-methods approach.

\section{Learning environments}

Despite decades of extensive research in various fields of study, definitions of learning environment still vary greatly. Common to most definitions is the aim to develop environments that support learners in their efforts to reach cognitive change, that is, to learn. Some frameworks consider learning environments more from the point of view of learners, some see the role of teachers as more significant, and some combine both perspectives for a joint definition. Manninen et al. (2007) define learning environment in terms of five different perspectives: pedagogical approaches, social and collaborative aspects, physical spaces, technologies used, and off-campus settings for contextual learning (e.g., museums as a place for inquiry and learning). Wang (2008) proposes a threedimensional model for learning environments by combining pedagogy, social interaction, and technology. This model was especially developed to guide teachers in effective ICT integration; it therefore provides a useful framework for investigating learning environments and learning experiences in the FC context. In the framework proposed by Wang (2008), pedagogy and social interaction create the core of learning environments, but they need to be supported by ICT. In the following sections, learning environments are discussed in detail, following this three-dimensional model.

\section{Pedagogical dimension}

The integration of student-centered teaching and learning approaches into higher education is a slow, time-consuming process. There have been several attempts to develop more collaborative teaching and learning practices, using various pedagogical methods and technologies (Murphy \& Sharma, 2010). These developing approaches contain various methods, such as discussion activities during lectures, the use of voting systems, and debates. Overall, scholars have 
suggested several ways to inspire students to participate more, especially during lectures (see Cruz e Costa, Ojala, \& Korhonen, 2008; Puranen, Helfenstein, \& Lappalainen, 2009). In the higher education context, Entwistle, McCune, and Hounsell (2002) explored the dimensions of a quality learning environment and emphasized the importance of students' experience of the extent to which the learning environment provides constructive feedback and supports the development of their understanding. Valtonen, Havu-Nuutinen, Dillon, \& Vesisenaho (2011) attempted to develop students' collaboration by creating shared lecture notes using technologies similar to Twitter. Altogether, these attempts represent efforts to steer teaching and learning practices toward the more collaborative and student-centered approach advocated by Harasim (1996). Still, these studies aimed to develop teaching and learning within the confines of lecture-hall-type teaching, that is, using the so-called broadcasting approach described by Harasim (1996). This can be seen as one of the reasons why the steps taken toward development have remained rather small.

In addition to the development processes described above, several approaches have attempted to steer higher education pedagogy toward a more studentcentered approach, that is, away from broadcasting, to knowledge construction (Harasim, 1996). Thus, pedagogies where teaching and learning are seen as a process of knowledge building through active student participation, student engagement, ownership, and collaborative activities have been introduced, including, for example, blended learning (Boelens, De Wever, \& Voet, 2017), inquiry-based learning (Loyens \& Rikers, 2011), and problem-based learning (Hung, Jonassen \& Liu, 2008). One example of blended learning is the FC approach, where students prepare for face-to-face meetings by familiarizing themselves with supportive pre-material, such as online video lectures (e.g., Tusa et al., 2018). This enables the face-to-face meetings to focus on challenging topics and higher-level cognitive activities through collaborative knowledgebuilding practices (Abeysekera \& Dawson, 2015; Talbert, 2017). Altogether, these models can be seen as ways to trigger the mechanisms of learning. According to Dillenbourg (1999), collaborative learning is a situation in which particular forms of interaction among people are expected to occur, which can further trigger learning mechanisms. Within these different pedagogical models, the aim is to create situations, to direct students to bring up their unique knowledge structures, and to create cognitive conflicts to support students' collaborative knowledge construction (Limo'n, 2001). These pedagogical approaches are important not only for learning mere content, collaborating, and searching for new knowledge but also for supporting the development of the $21^{\text {st }}$ century skills. Furthermore, these approaches can help students to confront meaningful and authentic tasks and further bridge the gap between higher education studies and future working life (McHaney, 2011).

Some scholars (see, e.g., Kirschner, Sweller, \& Clark, 2006), however, have critiqued the vast use and popularity of constructivist approaches, which lack guidance during instruction and can further lead to misconceptions or incomplete knowledge regarding the topic being studied. FC as a method for teaching and studying, as used in the course design researched in this study, 
addresses this concern by providing students with direct instructional guidance at the beginning of a new topic before proceeding to more student-centered methods that afford the students more autonomy and a more active role. Consequently, the teacher's direct guidance is concentrated at the beginning of the learning process, where, according to quite often used Bloom's taxonomy (Krathwohl, 2002) for setting learning outcomes, the student is only remembering and understanding new knowledge. Students then apply, analyze, evaluate, and create knowledge both individually and collaboratively during the face-to-face meetings, where the teacher's role gradually recedes, enabling students to effectively acquire new knowledge and learn. Therefore, as urged by Kirschner, Sweller, and Clark (2006), the shift from the teacher's direct guidance to students' self-direction in FC occurs and is supported only when students have an adequate level of prior knowledge.

\section{Social and collaborative dimension}

The ability and tendency to offer mutual support and transmit skills, technologies, beliefs, cultures, and so forth through social interaction has distinguished humans from other animals since early in humans' evolution (Richards, 2019). Through social constructivism, the importance of the social dimension in learning has become more widely understood, and its relevance has become one of the driving forces behind new pedagogical approaches such as peer instruction (Crouch \& Mazur, 2001) and FC (Bergmann \& Sams, 2012). Millis (2010) defines the social component as a crucial factor of meaningful learning, comprising elements of group interaction, communication, and collaboration. Collaboration engages students in communicating, learning and sharing, and constructing knowledge together by receiving and giving feedback in interactive activities (Dane, 2016). Manninen et al. (2007) further portray the social dimension as the learning climate. According to Wang (2008), the social design for a meaningful learning environment should include a safe space where learners-peers, teachers, and other experts-collaborate. Similarly, Baert, De Rick, \& Van Valckenborgh (2006) argue that students will only engage actively in their learning processes in a safe learning environment. Previous studies specifically assessing FC courses have shown that the learning climate was experienced as open (Kim, Kim, Khera, \& Getman, 2014) and safe and encouraging (James, Chin, \& Williams, 2014).

Several studies have considered the effects of collaboration in learning and found improvements in student achievement, engagement, and motivation (see, e.g., Johnson, Johnson, \& Smith, 2007). In heterogeneous groups in which students have different backgrounds and perspectives, collaboration has been found to boost creativity and deepen learning (Kozhevnikov, Evans, \& Kosslyn, 2014). Scager, Boonstra, Peeters, Vulperhorst, and Wiegant (2016) point out that, in addition to its cognitive benefits, collaboration may provide students with the social skills they will need in future working life. When the FC approach is implemented in higher education settings, collaborative and peer learning methods are often used during the in-class activities (Bishop \& Verleger, 2013; Talbert, 2017). Strayer (2012) found that students were more open to collaborating in a flipped course than they were in a traditional course; they also found that collaboration affected the perception of a positive learning 
environment. Additionally, Tusa et al. (2018) found that FC with collaborative tasks is more effective than traditional lecture-based instruction with collaborative tasks in medical education content learning. Kim et al. (2014), however, assert that if students are only provided with collaborative instructional activities during a course, they will neither directly bond with each other nor collaborate on tasks at a deeper level. Therefore, the teacher's role and the establishment of a positive learning climate are key components in creating a meaningful social learning environment.

Today, social networking and various virtual environments have renewed the social dimension, enabling students to acquire, filter, and use information anywhere, at any time (Oliver, 2016). McHaney (2011) states that students can obtain more knowledge collectively than even the best professor could hold alone. Thus, this change, where the advancements of technology transform social learning and collaboration, can be leveraged in teaching and learning settings.

\section{Technology}

Over the past several decades, the development of ICT has been rapid. Following these trends, numerous different approaches to teaching and learning have been designed and implemented. In the latest Horizon report (see Alexander et al., 2019), mobile learning and learning analytic technologies are identified as today's trends. The forecast for the near future highlights mixed or augmented reality and artificial intelligence, followed by virtual assistants for learning support, as the future deployments that will be developed in the next four to five years.

In teaching and learning, Poitras \& Lajoie (2013) define technology through two perspectives: the benefits of utilizing ICT in teaching and learning and the ways of using technology with the support provided for its usage. West and Thompson (2015) describe the current state of ICT in educational practices with the concept of mobile knowledge paradigm. Through technological development, learning has become ubiquitous in everyday life, and learners or users can immerse themselves in technology (Imms, Cleveland, \& Fisher, 2016).

As Thornburg (2013) argues, however, novel technologies should not be used only to replicate old methods with new tools. Moreover, some scholars have advocated a more considerate view of technology usage, stating that technological considerations should not supplant pedagogical considerations (Abeysekera \& Dawson, 2015; Talbert, 2017). Consequently, technology should be understood as an instrument to diversify learning environments and to support students with different learning needs, especially when considering current views on learning theories behind technology usage (Bergmann \& Sams, 2012; Mishra, Koehler, \& Henriksen, 2010; Kim et al., 2014).

The technological component of learning environments is understandably more prominent in a technology-enhanced learning environment, such as in the FC approach, where technology enables pre-class learning to occur anywhere, at any time and can enhance learning during in-class activities and support 
teachers' instruction (Lasry, Dugdale, \& Charles, 2014). Similarly, Ifenthaler (2010) asserts that learning can be more personalized through the possibility of learning without time or place constraints. Sointu et al. (2019) discovered that students saw their FC course teachers as being more positive with regard to the use of technology from the perspective of technological pedagogical content knowledge (TPACK) (Mishra \& Koehler, 2006), while McNally et al. (2017) found that students preferred using technology by themselves as a learning support over other aspects of the FC environment. Although much research has focused on identifying the usage of technology in the FC approach generally, however, the literature currently lacks substantial evidence on student perceptions regarding technology in FC.

\section{Purpose of the study}

The aim of this study was to describe students' experiences of satisfaction in courses implementing the FC approach. For this purpose, the students were divided into three groups: (1) minimally satisfied, (2) slightly satisfied, and (3) satisfied. Both quantitative and qualitative methods and data were used to explore and explain the different experiences of these groups in relation to their perspectives regarding the key components of learning environments.

Based on the aim of this study, our research questions were as follows:

1. How is students' level of satisfaction with the flipped classroom approach related to the pedagogical, social, and technological dimensions of learning environments?

2. How do students describe their preferred learning environments in the flipped classroom context?

\section{Methods}

\section{Participants}

The participants in this study were enrolled in university courses in which the teachers had deployed FC as a novel approach for teaching the content of their courses. A total of 24 independent courses in multiple domains were flipped, including forestry, physics, biology, education, and medicine. All the courses were taught in the academic year 2016-2017 at one Finnish university. Overall, the convenience sample included $414\left(N_{\text {female }}=300,72.5 \% ; N_{\text {male }}=114,27.5 \%\right)$ higher education students, of whom $232(56.2 \%)$ were first-year students. The mean age of the participants was 26.19 years $(S D=7.58)$. The students were asked to complete an electronic questionnaire both at the beginning and at the end of the courses. The convenience sample was based on the fact that participation in the research was voluntary, and the response rate varied between the courses, from $25 \%$ to $75 \%$.

Prior to the research, all the participants received information on participation in the study, including ethical considerations. Participation in the study was voluntary for both students and teachers, and only responses from participants who had given informed consent were measured and analyzed. Non- 
participation in the study did not affect the final grading or course completion. All data were carefully protected in accordance with the EU's General Data Protection Plan (GDPR) and both the national and institutional policies.

\section{Course design}

The FC approach was a novel model for all the participating teachers, that is, they were all using FC to plan and teach their courses for the first time in their teaching practices. Hence, after the teachers decided to start to flip their courses, they were enrolled in specific institutional FC training. The training was provided by a team of experts responsible for the implementation of FC throughout the university; these experts included teachers, researchers, designers, and administrative experts. The teachers received a comprehensive training package containing supportive material, individual and group support, peer group support through tutoring, and assistance in the form of online video lectures for learning the FC approach, course planning and implementation, and data collection for practice-based research. This support was available for the teachers throughout the FC implementation.

The institutional FC training was designed to emphasize five carefully chosen elements, as shown in Figure 1. The basis of the training was curriculum work, as it would be guiding the entire process of planning, preparing, designing, developing, implementing, and assessing the courses and is significantly different in the FC model from most teachers' usual teaching practices. The next element, pedagogical practices in class, contained information and instruction regarding the teacher's role in the FC model, such as how to organize the contact lessons so that they would support student learning in the best way. As technology is deployed in various ways in the FC method, technology in education was covered in depth during the training. Various devices and applications, tutorials for their usage, and the benefits of technology for both teaching and learning were discussed throughout the training. Moreover, students' guidance and counseling practices focused on ways of familiarizing and supporting students with this novel study method. Finally, assessment practices placed particular emphasis on the use of formative assessment and its beneficial impact on student learning. 


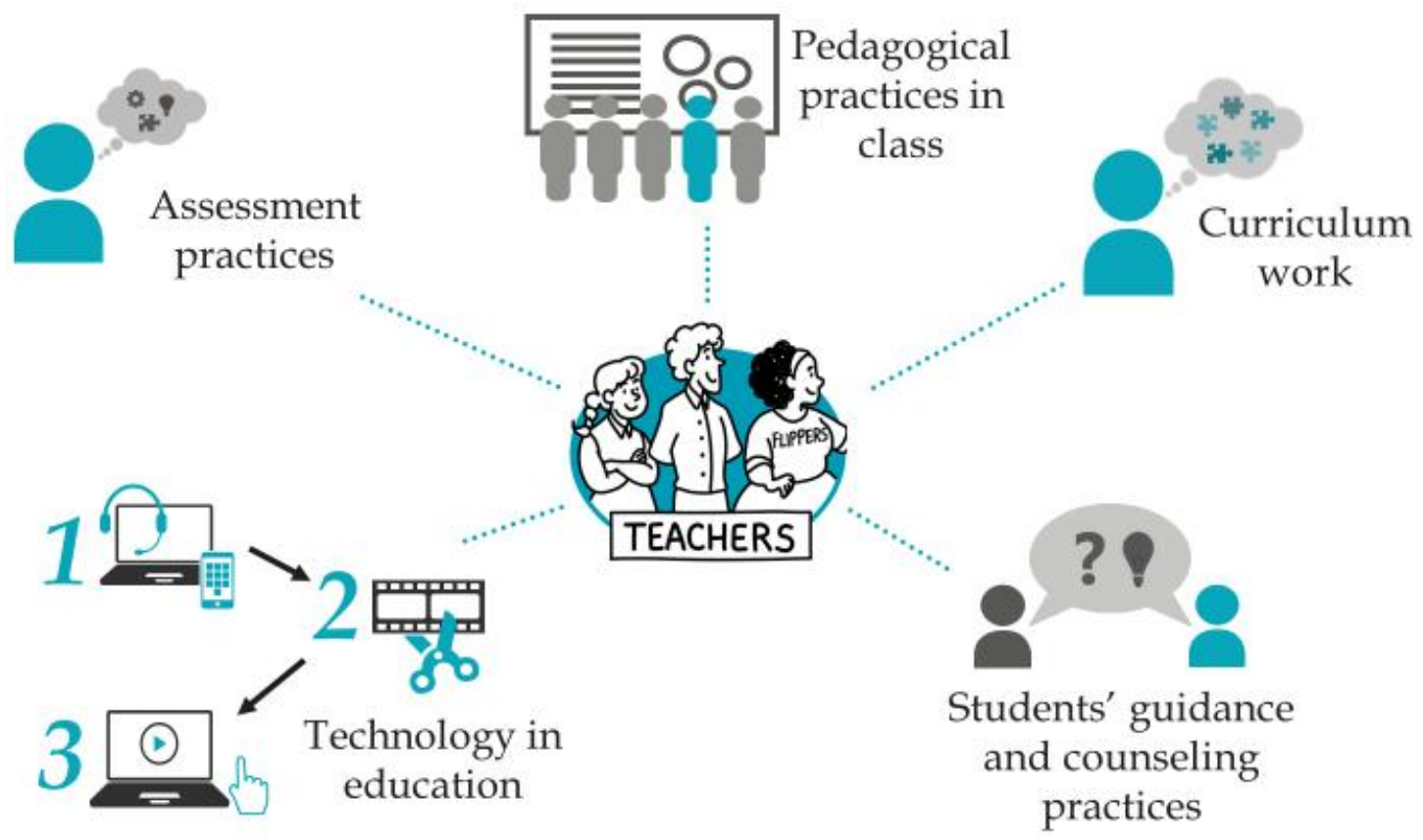

Figure 1: Elements of FC institutional training

\section{Measures and Analyses}

To capitalize on the strengths of both quantitative and qualitative methods, a mixed-methods approach was used in this study (Creswell \& Plano Clark, 2018). The questionnaire battery included several instruments and variables that were designed, modified, and pilot-tested for the purposes of this research. The instruments were carefully chosen to investigate students' perceptions of the courses. The qualitative data were derived from open-ended answers to an open-ended question in the questionnaire: "What is a good learning environment like?" In both the quantitative and qualitative analyses, Wang's (2008) three-dimensional model for learning environments was followed.

The first section of the questionnaire investigated the pedagogical dimensions of the learning environment, and students' experiences with regard to the following five elements were measured: (1) their teachers' readiness to combine pedagogy and content knowledge in the course (PCK; three items); (2) pedagogical experiences in terms of teaching aimed at understanding (UND; four items); (3) constructive feedback (FEED; three items) received during the course; (4) the level of experienced difficulty (DIFF; three items) of the course; and (5) guidance received in the FC study method (GUID; five items). The PCK instrument was adapted from the TPACK-21 questionnaire by Valtonen et al. (2017), the UND and FEED instruments were selected from the Experiences of Teaching and Learning Questionnaire (ETLQ) by Entwistle et al. (2002), and the DIFF and GUID instruments were created exclusively for this research. The second section focused on students' perceptions of the social dimension by measuring the following: (1) collaborative working (COLL; five items) by Wang, 
MacCann, Zhuang, Liu, \& Roberts (2009); (2) support from other students (SUPP; three items) by Entwistle et al. (2002); and (3) safe atmosphere for learning (SAFE; three items) with an instrument created specifically for this study. The third section investigated the technological dimension by eliciting students' reflections on two elements: (1) their readiness to use ICT for study purposes (TECH21; four items), partially by Valtonen et al. (2017); and (2) how they experienced the added value of ICT in education (AV-ICT; four items) by Chen (2011).

Exploratory factor analysis (EFA; not reported in this study due to space constraints) was run to analyze the reliability and construct validity of the instruments. The internal consistency (Cronbach's a) of all subscales exceeded the criterion of 0.7 (Nunnally, 1978). All the subscales, with sample items from each instrument and their alphas, are presented in Table 1, alongside the corresponding learning environment dimension.

Table 1: Description of the subscales with sample items, division into learning environment dimensions, and internal consistency of the subscale measures with Cronbach's alpha (a)

\begin{tabular}{|c|c|c|c|c|}
\hline $\begin{array}{l}\text { Sub- } \\
\text { scale }\end{array}$ & Description & Sample item & $\begin{array}{c}\text { Learning } \\
\text { environment } \\
\text { dimension }\end{array}$ & a \\
\hline UND & $\begin{array}{l}\text { Teaching aimed at } \\
\text { understanding }\end{array}$ & $\begin{array}{l}\text { "Teachers supported students in } \\
\text { scientific thinking." }\end{array}$ & & .84 \\
\hline DIFF & $\begin{array}{l}\text { The level of } \\
\text { experienced difficulty } \\
\text { in the FC course }\end{array}$ & $\begin{array}{l}\text { "Studying pre-materials was } \\
\text { highly time consuming." }\end{array}$ & & .78 \\
\hline PCK & $\begin{array}{l}\text { Students' views on } \\
\text { teachers' pedagogical } \\
\text { content knowledge }\end{array}$ & $\begin{array}{l}\text { "My teachers use a variety of } \\
\text { teaching methods to make the } \\
\text { subject matter easy to } \\
\text { understand." }\end{array}$ & Pedagogical & .84 \\
\hline GUID & $\begin{array}{l}\text { Guidance received in } \\
\text { the FC study method }\end{array}$ & $\begin{array}{l}\text { "During the course, students } \\
\text { were adequately instructed in the } \\
\text { FC as a study method." }\end{array}$ & & .86 \\
\hline FEED & Constructive feedback & $\begin{array}{l}\text { "Feedback I received during the } \\
\text { course assignments helped me to } \\
\text { understand topics I did not fully } \\
\text { understand." }\end{array}$ & & .80 \\
\hline SUPP & $\begin{array}{l}\text { Support from other } \\
\text { students }\end{array}$ & $\begin{array}{l}\text { "Students supported each other } \\
\text { and tried to provide help when } \\
\text { needed." }\end{array}$ & & .83 \\
\hline COLL & Collaborative working & $\begin{array}{l}\text { "Studying in groups improves } \\
\text { the quality of my learning." }\end{array}$ & Social & .85 \\
\hline SAFE & $\begin{array}{l}\text { Creation and } \\
\text { maintenance of a safe } \\
\text { atmosphere for } \\
\text { learning }\end{array}$ & $\begin{array}{l}\text { "The course had a safe } \\
\text { atmosphere to think critically } \\
\text { about the study content during } \\
\text { the lessons." }\end{array}$ & & .82 \\
\hline TECH2 & $\begin{array}{l}\text { Students' readiness to } \\
\text { use ICT for study } \\
\text { purposes }\end{array}$ & $\begin{array}{l}\text { "I know how to use ICT } \\
\text { effectively to support my } \\
\text { learning." }\end{array}$ & Technological & .88 \\
\hline
\end{tabular}


AV-ICT The added value of "ICT use in learning helps me to
ICT in education

.85

To investigate how perceptions regarding the different aspects of the learning environment differed between groups, a grouping variable explaining how students experienced the FC method in their studies was formed. Based on EFA, a composite score, experience of satisfaction with FC (ESFC), was calculated with the following variables: "In my opinion, the course functioned well as a whole," "Pre-class materials and contact teaching complemented each other well," "Pre-class materials and contact teaching as a whole provided an effective framework for learning the content matter," "The use of pre-class materials effectively helped to prepare for contact teaching," and "The study methods used in contact teaching helped to understand more comprehensively the topics of pre-materials." The students responded using a 6-point Likert-type scale ( $1=$ strongly disagree $-6=$ strongly agree). The internal consistency of ESFC was acceptable $(\alpha=0.91)$, and it exceeded the cut-off criterion of 0.7 (Nunnally, 1978). Based on the data, three groups were created: (1) minimally satisfied $(N=81),(2)$ slightly satisfied $(N=151)$, and (3) satisfied $(N=181)$. Cut-off criteria was based on the original Likert-type scale.

The data were analyzed in three stages. First, we analyzed the quantitative data from the questionnaire battery, using SPSS v25 to present the descriptive statistics and to investigate both general and successful features of the flipped course. Second, we ran a one-way analysis of variance (ANOVA) with post-hoc tests (Bonferroni) to compare the groups based on ESFC in terms of mean differences. With ANOVA, the effect sizes were calculated by the omega squared $\left(\omega^{2}\right)$, which, according to Field (2018), measures the effect size in the population more reliably than the partial eta squared $\left(\eta^{2} \mathrm{p}\right)$. Kirk (1996) suggests that $\omega^{2}$ between .01 and .06 can be considered a small effect size, $\omega^{2}$ between .06 and .14 can be considered a medium effect size, and $\omega^{2}$ greater than .14 can be considered a large effect size. Third, we analyzed the qualitative data from the open-ended answers via theory-guided content analysis. By means of abductive reasoning (Tuomi \& Sarajärvi, 2018), we connected the emerging findings with existing research on the studied phenomenon. In other words, the answers were first read to gain an overview of the data. The data were then coded, and the codes sorted by the Atlas.ti program into three categories according to Wang's (2008) model: social, pedagogical, and technological dimensions. Finally, the codes were organized as sub-categories based on their similarities. To increase the reliability of the results, three researchers were consulted during creation of the categories and sub-categories.

Later in the analysis, we compared the open-ended answers to determine whether they supported or contradicted the quantitative findings. During the analysis, we noticed the complementary nature of the different learning environment dimensions: A single student mention could be assigned under more than one dimension. The students also referred, to some extent, to physical space; thus, these mentions could not be assigned under Wang's (2008) threedimension model. Regarding the foundation of mixed-methods studies, Creswell and Poth (2018) describe that new classes can be formed from 
subclasses outside the theory. Thus, the analysis of the qualitative data was guided by a data-driven perspective, but the dialogue between the data-driven and theory-based approaches was continuous.

\section{Results}

Statistical differences between groups in terms of their perceptions regarding the aspects of the learning environment

The results uncovered differences between students' perceptions of the FC courses in terms of all the investigated dimensions of the learning environment. One-way ANOVA with post-hoc tests (Bonferroni) was used to investigate the effect of the overall course preferences on the different aspects identified. The results of the mean scores for the FC pedagogical dimensions are presented in Table 2. The largest statistically significant differences in mean scores were found with regard to GUID $\left(F\left(2.41=172.90 ; p<.001 ; \omega^{2}=.45\right)\right.$, but large statistically significant differences were also found with regard to UND ( $F(2.410$ $\left.=85.43 ; p<.001 ; \omega^{2}=.29\right)$, FEED $\left(F\left(2.408=68.05 ; p<.001 ; \omega^{2}=.25\right)\right.$, and PCK $\left(F\left(2.410=59.65 ; p<.001 ; \omega^{2}=.22\right)\right.$. The effect sizes measured with $\omega^{2}$ indicated large differences in all four of the abovementioned elements. Based on the posthoc tests, there were highly statistically significant differences $(p<.001)$ between all the groups; however, there were no differences between the groups in terms of the student-reported DIFF. This indicates that the more satisfied the students were with the flipped courses, the more they received guidance on the FC study method and constructive feedback during the courses. In addition, the students who were satisfied with the courses were more likely than the minimally satisfied students to perceive that the teaching was aimed at understanding and that the teachers had high pedagogical content knowledge.

Table 2: One-way ANOVA results between groups of satisfaction of FC pedagogical dimensions

\begin{tabular}{|c|c|c|c|c|c|c|c|c|c|c|c|}
\hline \multirow{2}{*}{\multicolumn{2}{|c|}{ Group name }} & \multicolumn{2}{|c|}{ UND } & \multicolumn{2}{|c|}{ DIFF } & \multicolumn{2}{|c|}{ PCK } & \multicolumn{2}{|c|}{ GUID } & \multicolumn{2}{|c|}{ FEED } \\
\hline & & $M$ & $(S D)$ & $M$ & $(S D)$ & $M$ & $(S D)$ & $M$ & $(S D)$ & $M$ & $(S D)$ \\
\hline ] & $\begin{array}{l}\text { Minimally } \\
\text { satisfied }\end{array}$ & 3.02 & $(0.85)$ & 3.10 & (1.22) & 3.48 & $(0.89)$ & 3.63 & $(0.83)$ & 2.79 & $(0.80)$ \\
\hline ) & $\begin{array}{l}\text { Slightly } \\
\text { satisfied }\end{array}$ & 3.74 & $(0.51)$ & 3.05 & $(0.95)$ & 4.19 & $(0.63)$ & 4.54 & $(0.55)$ & 3.44 & $(0.66)$ \\
\hline 3 & Satisfied & 4.14 & $(0.64)$ & 3.07 & (1.04) & 4.58 & $(0.94)$ & 5.17 & $(0.57)$ & 3.91 & $(0.73)$ \\
\hline & Total & 3.77 & $(0.76)$ & 3.07 & (1.04) & 4.26 & $(0.94)$ & 4.64 & $(0.85)$ & 3.52 & $(0.83)$ \\
\hline
\end{tabular}

Note. UND teaching aimed at understanding, DIFF the level of experienced difficulty, PCK pedagogical content knowledge, GUID guidance received for the study method, FEED constructive feedback. $M$ mean, $S D$ standard deviation.

In the social dimension (Table 3), highly statistically significant differences $(p<.001)$ were found between all the groups in terms of all three of the measured aspects. The largest differences in group mean scores were found in SAFE $\left(F\left(2.197=62.09 ; p<.001 ; \omega^{2}=.26\right)\right.$, with a large effect size between groups measured with $\omega^{2}$; meanwhile, students' perceptions also differed with regard to 
$\operatorname{SUPP}\left(F\left(2.228=28.44 ; p<.001 ; \omega^{2}=.13\right)\right.$ and $\operatorname{COLL}(F(2.281=10.62 ; p<.001 ;$ $\left.\omega^{2}=.05\right)$. The effect size for SUPP was medium, and the effect size for COLL was small, as indicated by $\omega^{2}$. The better the students' perceptions of the flipped courses, the more they experienced the course atmosphere as safe, the more support they received from their peers, and the more they collaborated with one another.

Table 3: One-way ANOVA results between groups of satisfaction of FC social dimensions

\begin{tabular}{|c|c|c|c|c|c|c|c|}
\hline \multirow{2}{*}{\multicolumn{2}{|c|}{ Group name }} & \multicolumn{2}{|c|}{ SUPP } & \multicolumn{2}{|c|}{ COLL } & \multicolumn{2}{|c|}{ SAFE } \\
\hline & & $M$ & $(S D)$ & $M$ & $(S D)$ & $M$ & $(S D)$ \\
\hline 1 & $\begin{array}{l}\text { Minimally } \\
\text { satisfied }\end{array}$ & 3.52 & $(0.92)$ & 3.48 & $(1.02)$ & 3.22 & (0.88) \\
\hline 2 & Slightly satisfied & 3.96 & $(0.68)$ & 3.83 & $(0.85)$ & 3.95 & $(0.56)$ \\
\hline 3 & Satisfied & 4.30 & $(0.69)$ & 4.07 & $(0.97)$ & 4.29 & $(0.61)$ \\
\hline & Total & 4.02 & $(0.79)$ & 3.87 & $(0.96)$ & 3.96 & $(0.76)$ \\
\hline
\end{tabular}

Note. SUPP support from other students, COLL collaborative working, SAFE creation and maintenance of a safe atmosphere for learning. $M$ mean, $S D$ standard deviation.

When the technological dimensions were investigated (Table 4), differences between the groups were found in terms of both AV-ICT $(F(2.294=13.73 ; p<$ $\left..001 ; \omega^{2}=.13\right)$ and TECH21 (F 2.252 = 29.46; $\left.p<.001 ; \omega^{2}=.06\right)$. Both the measured elements had medium effect sizes, as measured with $\omega^{2}$. The differences between all the groups were highly statistically significant $(p<.001)$. The students who were satisfied with the FC courses not only felt more ready to use technology in their studies but also rated the added value of technology higher than the students who were minimally satisfied with the courses.

Table 4: One-way ANOVA results between groups of satisfaction of FC technological

\begin{tabular}{|c|c|c|c|c|c|}
\hline & \multirow[b]{2}{*}{ Group name } & \multicolumn{2}{|c|}{ ТECH 21} & \multicolumn{2}{|c|}{ AV-ICT } \\
\hline & & $M$ & $(S D)$ & $M$ & $(S D)$ \\
\hline 1 & Minimally satisfied & 3.68 & $(0.92)$ & 3.93 & $(0.91)$ \\
\hline 2 & Slightly satisfied & 3.95 & $(0.78)$ & 4.19 & $(0.74)$ \\
\hline 3 & Satisfied & 4.27 & $(0.93)$ & 4.69 & $(0.74)$ \\
\hline & Total & 4.04 & $(0.90)$ & 4.36 & $(0.83)$ \\
\hline
\end{tabular}

Note. TECH21 students' readiness to use ICT for studying, AV-ICT the added value of ICT in education. $M$ mean, $S D$ standard deviation. 


\section{Qualitative results}

Using the theoretical dimension divisions as a guideline, we divided the students' open-ended answers into three categories: social dimensions, pedagogical dimensions, and technological dimensions. The qualitative analysis, however, revealed various subcategories that had characteristics of more than one category. Therefore, two new categories were formed to better portray the students' views of a good learning environment: (1) Socio-pedagogical dimension and (2) Technological-pedagogical dimension. Finally, the students' perceptions were grouped into five main categories, with 20 subcategories related to the preferred aspects of the learning environment.

\section{Social dimensions}

The first main category, social dimensions, was the most frequently mentioned, with 196 references by 178 students (43\%). The students reported different qualities and characteristics of the mental and psychological environment, atmosphere, and social interactions in the flipped course. Consequently, this category included two sub-categories: (1) atmosphere and (2) collaboration and support. The students described a pleasant atmosphere as an encouraging, open, and safe atmosphere where everyone is recognized as an individual and different opinions are allowed. Further, an open atmosphere was perceived as a facilitator for learning.

"During the lessons, open. In general, open, as that enables learning something new."

"Lectures should be interactive, where knowledge and experiences are shared between students and teachers."

"A good learning environment is encouraging, where everyone's answers and opinions are appreciated."

In the second sub-category, the students highlighted the importance of reciprocal respect and trust between the teacher and the students, with support not only available but also received from teachers and peers. In addition, the students appreciated that the courses included collaboration, with teachers and students discussing, questioning facts, searching for solutions, and learning together. As a prerequisite for collaboration, students should feel that it is safe for them to ask any kind of question without fear of being laughed at. The students appreciated that when they are placed at the center of the learning situation, the teachers can personalize their teaching, and the whole class can promote an atmosphere that accepts difference. The students reflected on how the learning situation should be organized to support both collaborative learning and a positive atmosphere.

"Teachers need to be close to the students so that students feel they can go to ask the teachers anything if they have any questions." 
"That you receive peer support from other students and you dare to ask for help when you need it."

"An open place to express your opinion and ask 'stupid questions.' Nobody is criticized, even if someone does not know everything."

"In a good learning environment, teachers trust adult learners. Distrust is caused by giving too many tasks that have not been discussed or explained at all."

"To develop my own thinking, it is important for me to listen to other students' views on how they see certain phenomena. This helps me to see multiple different aspects of different phenomena."

The qualitative results indicated that when the social learning environment contains the aspects described above, learning becomes meaningful and will also continue after the lectures. This engages students in their learning, rendering them active and responsible learners.

"[In a good learning environment], topics are discussed among peers outside the lectures as well."

\section{Pedagogical dimensions}

The second main category, with 151 references by 137 students (33\%), was the pedagogical dimensions, including mentions concerning the teacher's role in support for learning processes and the organization of study events. This category contained three sub-categories: (1) personalized teaching, (2) teachers' pedagogical knowledge and skills, and (3) applying learning and skills for the future. Most importantly, the students wished that teachers would consider each student as an individual, considering different learners and their learning strategies by adopting a personalized and flexible approach to teaching and learning. To promote such differentiated instruction, various teaching methods should be used, enabling students to choose the ones that are suitable for them.

"A good learning environment offers alternative ways of studying because everyone learns differently: Some learn better when working independently; others [learn better] in groups. Some learn by 'doing'; others [learn] by listening."

"Versatile teaching methods together. A lecture lasting multiple hours is pedagogically insane, and it becomes impossible to concentrate on listening for such a long time."

"A good learning environment promotes learning and is appropriate in the moment. There exists not only one good learning environment, but the 'goodness' of the environment always depends on the group and the topic being studied." 
The students expressed multiple views on the teachers' pedagogical knowledge and skills and on what characterizes an expert teacher. In terms of teachers' tasks, students identified the requirement to design high-quality courses and lectures in which students can develop their critical thinking skills. In addition, teachers are expected to motivate and encourage students, providing formative assessments and giving constructive feedback.

"Teachers should constantly motivate students in different ways. Those who want a challenge should be offered a challenge, but those who are struggling should be offered supportive tasks."

"Everything starts with professional and enthusiastic teachers who can motivate and engage students. They have a passion for their work."

"In a good learning environment, you receive concrete feedback on your progress. The usual way of receiving a grade without feedback on an assessment does not describe the strengths or weaknesses of the student; [it only describes] the overall performance."

The students also highlighted the practical applicability and usefulness of the knowledge acquired. They expressed a preference for studies that serve as a springboard for future working life, where the knowledge and skills can be employed. As an example, the use of real-world simulation learning environments in teaching and learning was seen as beneficial to working life and its practices.

“- - giving tools to be put into practice. - - For example, incorporating participatory methods and learning through simulations into any course where these methods could be included would be important and useful."

“- - supporting the student's own goals, taking into account the demands of working life."

\section{Technological dimensions}

In the third main category, technological dimensions, 36 references $(8 \%)$ were identified and assigned under three sub-categories: (1) well-functioning devices, (2) flexibility, and (3) social interaction with technology. The students found that technological tools and applications were used to a great extent during the FC courses. They also reported that FC as a study method requires well-functioning technological devices and applications. Overall, the students saw potential in the technological learning environment and in the use of technology for pedagogical purposes but were not very satisfied with the current technology usage. Most mentions were made with regard to the functionality, availability, and modernity of the technologies used. Furthermore, the students expected to receive an introduction to and guidance for the different technologies. 
"Digital environments need to be functional, unlike in Moodle, where videos only run when they happen to feel like it."

"Modern devices, but not necessarily too much fuzz with them."

"In a good learning environment, technology would be used in a variety of ways, and students would be guided in its utilization."

The students saw great benefits in using technology to increase the flexibility of teaching and learning. Technology enables studying to become more personalized when learning can occur anywhere and at any time. Consequently, students can better adapt their studies to their different situations in life.

"The use of e-learning platforms facilitates learning and makes it place-independent."

"Flexible, you can study wherever and whenever you like, but there is also the possibility of contact learning."

"Takes into account different life situations and schedules, that is, is flexible, permissive."

The students emphasized the importance of social interaction and collaboration in technological environments, as different technologies are developing rapidly and digital learning is becoming increasingly popular. Thus, even if students are working on the same task at the same time without being in the same physical place, they should be able to interact in an effortless way.

"A good learning environment is a functional and complete package that enables you to work and interact wherever you are."

"Functional on all devices, enabling work in groups."

\section{Socio-pedagogical dimension (new dimension based on data)}

The fourth main category, socio-pedagogical dimension, was composed primarily of mentions that reflected on teaching and studying methods that enable learning, including various methods of collaborative learning and teamwork, although there were also students who do not favor collaborative methods. Therefore, students should have the opportunity to influence their own learning situations. Moreover, the students reported that in a good learning environment, students are motivated, active, and curious about the subject being studied, that is, a high level of emotional participation in learning is characteristic of a good learning environment.

“- - it is necessary to embed some group discussion, working together, and so forth - - In addition, collaboration, seminars, exercises during contact lessons, group work, and so forth feel meaningful and fuel professional self-esteem." 
“- - taking into account different learning ways. For example, students are not forced to engage in teamwork but are given the opportunity for it, but they also have the option of working alone."

Technological-pedagogical dimension (new dimension based on data)

As technology was greatly included in the FC courses, the students considered it important to consider the effective integration of technology into the teaching and learning situations. Thus, several students described the technologicalpedagogical dimension, which constituted the fifth main category. In order for technology usage to be meaningful and form part of a good learning environment, it should add value to teaching and learning. The digital material used in the FC courses was mostly experienced as positive, although some of the students believed that technology could have been utilized even more. The students expressed the belief that technology enables more freedom and versatility in choices and that it facilitates the development of skills that cannot be cultivated through traditional methods.

"Technology usage should not be imposed simply because it is 'cool'."

"Generally, I would like exams to be replaced with other assignments or even electronic exams because I can produce better writing with a computer. In addition, using data in an online format improves information-seeking skills, which are more important in today's world than remembering all the trivia."

"Students should be able to freely use technology when needed, but there should also be opportunities to access traditional data sources and data collection. The videos were really good for studying!"

"Students should have access to comprehensive online material at any time when needed to review and self-study the content."

Moreover, in a good learning environment, the combination of contact and distance learning should be flexible and versatile.

"Versatile. Takes into account students who want contact teaching but also students who would rather study remotely. The video-recorded lectures and contact teaching complementing the videos provide a good learning environment."

"Suitable proportion of contact teaching and online assignments." 


\section{Discussion}

The aim of this study was to investigate students' satisfaction with the flipped classroom (FC) approach in relation to their perspectives regarding the key components of learning environments, using a mixed-methods approach. For this purpose, the students were divided into three groups based on their views with regard to their satisfaction with FC. We used both quantitative and qualitative methods to investigate the different experiences of the three groups in relation to their perspectives regarding the key components of learning environments.

This study found that there were significant differences between the three groups in terms of several elements within the three-dimensional learning environment model proposed by Wang (2008). Both the quantitative and qualitative results showed that the pedagogical and social factors affected the students' view of a successful learning environment to the greatest extent. Based on the ANOVA and post-hoc tests, there were highly statistically significant differences $(p<.001)$ between all the groups in terms of all the measured elements, except in the experienced difficulty of the courses. The students' views with regard to sufficient guidance received in the FC study method, teaching aimed at understanding, the teacher's pedagogical content knowledge, a safe course atmosphere, support from peers and teachers, and the use of technology in learning exerted the most significant effect on explaining the success of a FC course. Together, these results agree with the findings of O'Flaherty et al. (2015), who identified the significant elements of FC through an extensive literature review. The open-ended answers supported the elements found through ANOVA by explaining the elements in greater depth and indicating the relationships between these elements. These open-ended answers reinforced the complementary nature of the measured learning environment elements, as highlighted by Wang (2008): Two new dimensions emerged and were created from the data to describe how the pedagogical considerations complemented the social and technological aspects.

The major differences between the groups were found in their perspectives regarding the guidance received in the FC study method, creation and maintenance of a safe atmosphere for learning, and teaching aimed at understanding. Thus, the more positive the students' perceptions of their course experience were, the more comprehensible they found the courses and the instructional material. This result further supports the findings of O'Flaherty et al. (2015), who state that pre-assignments and contact teaching should form a meaningful entirety so that students will both understand the FC method and be motivated to review the pre-material. In addition, perceptions regarding the creation and maintenance of a safe atmosphere for learning in the course that tolerated divergent opinions and critical questions significantly explained positive course experience. As described in the open-ended answers, a safe atmosphere should include support from peers and teachers, constructive feedback, the teacher's pedagogical and content knowledge, and guidance in the course. These can create a safe, open, relaxed, supportive, and respectful mental and psychological atmosphere where each student is welcomed. Moreover, this 
study found that the more positive the students' experience with the FC was, the better able the courses were to promote students' overall understanding of the subject and the discipline as a whole. The open-ended answers were greatly in line with the quantitative results. Consistent with the results obtained by Tusa et al. (2018), who found that students acquired skills that would be useful in their future working lives through the FC study method, our findings showed that the students expected higher education to prepare them for their future working lives, helping them to apply their knowledge and challenging them to develop their own critical thinking skills. Consequently, FC as a study method has its place in improving higher education students' $21^{\text {st }}$ century skills, as stated by Voogt and Pareja Roblin (2012), and further enabling the transformation in higher education urged by Harasim (1996).

Moreover, strong evidence was found in both the quantitative and qualitative analyses with regard to the effect of the constructive feedback received and the teacher's pedagogical content knowledge. The students emphasized the diversity and variety of teaching methods, the expertise and pedagogical skills of the teacher, and the constructive feedback and assessments received throughout the course. This substantiates the findings obtained by Tusa et al. (2018), who found that systematic individual feedback from the teacher in the middle of the learning process improved students' learning experience. Significant differences were found between the three groups in terms of the students' views with regard to collaboration with their peers. Although these differences and their practical significance remained small, in the open-ended answers, collaboration and peer support emerged from the data as noteworthy factors. The social dimension in a good learning environment was described as respectful and confidential. This is in accordance with the findings of Strayer (2012) and Forsey, Low \& Glance (2013), suggesting that flipped teaching can increase students' openness to collaboration and give them a more positive learning experience, both in their views on meaningful learning environments and in their experiences with the novel learning method.

The three groups differed significantly in terms of the students' perceptions with regard to the use of technology in teaching and learning. Consequently, the students recognized the importance and potential of technology in different teaching and learning situations, believing that through technology they can acquire skills that cannot be developed through traditional methods. The technology used in their FC courses and the combination within pre-class and in-class activities were experienced as adequate. Most of the students requested more extensive use of appropriate technology applications in learning settings; however, only a small number mentioned specifically how technology could be used as a tool for learning, such as through fostering critical or creative thinking. Corroborating the findings obtained by Ossiannilsson (2018), some of the students described technology as enabling flexible learning without time or space restrictions and integrating freedom and versatility into studying and learning. In addition, the students emphasized the need for well-functioning and available devices. 


\section{Conclusion}

The findings of this study emphasize the importance of the teacher's role, as the teachers' actions exerted an influence on students' positive experience with regard to each of the studied learning environment dimensions during the FC courses. The elements that most influenced students' positive experienceguidance received in the FC study method, teaching aimed at understanding, the teacher's pedagogical content knowledge, the creation and maintenance of a safe atmosphere for learning, support from peers and teachers, and students' views on technology usage-are all strongly connected to the teacher's knowledge, choices, and actions. Moreover, most of the students urged that students should be at the center of the teaching and learning situation in a good learning environment. This student-centered perspective also relates to the teacher's methodological choices. Bingham (2011) emphasizes the teacher's role in organizing conditions conducive to teaching and learning while expressing concerns over teachers' decreasing future importance in a world where a vast amount of online material is available and can be accessed anywhere, at any time. Overall, our findings strengthen the importance of the teacher in facilitating learning and the promotion of positive learning experiences. Perhaps a solution for the development of higher education could involve "collecting the cherries of the cake for learning", that is, combining the best parts of online teaching and face-to-face teaching with thoughtfully sequenced teaching for learning, as is enabled by FC. In the FC approach, this means time and location flexibility for students and the fact that they are better prepared for contact meetings. In the contact meetings, teachers can be pedagogical experts by creating a safe atmosphere for students and content experts by exposing their knowledge for students to use, as students have engaged with pre-materials to better prepare themselves for learning. This all requires pedagogical expertise, as does offering students guidance and counseling in the teaching approach, which is of paramount importance for promoting learning satisfaction. This can also influence the content learning and afford students opportunities to learn the $21^{\text {st }}$ century skills. Given these findings, it seems that attention should be further paid to these areas in teacher training in preparation for deploying the FC approach. These findings could serve as a future reference in the development of teacher training courses in the FC approach, leading to the creation of training that highlights the pedagogical, social, and technological aspects that have been validated in this study. Therefore, we recommend considering the elements of FC (Figure 1) and the results of this study in the development of teacher training and university pedagogy.

\section{Limitations and future research}

The generalizability of these results is subject to certain limitations. First, although the psychometric properties of the instruments were all pilot-tested and found adequate and most of them have been used extensively in previous research, the psychometrics were not fully reported or analyzed widely in this study. More research on the psychometrics is needed. Additionally, stronger quantitative methods such as structural equation modeling (SEM) is important to be used in the future. Second, the research data were derived from questionnaires administered to students from only one institution, thus no 
demographic effect could be ascertained. Therefore, more comprehensive samples are needed in the future. Third, the students were grouped based on their responses regarding the experience of satisfaction with FC. Thus, the students were not grouped based on their gender, major, or academic year of studies, and so forth. A further study could assess in greater depth the individual factors predicting the learning experience in an FC course. Fourth, more work is needed to explore what affects both positive learning experiences and positive teaching experiences in general. Fifth, further multimethod research is needed to verify the results obtained in this study, thus ensuring that they are not merely attributable to response bias. The fact that the students did not differ in terms of how difficult they thought the courses were, however, may be a sign that the differences in terms of their experiences with regard to the other factors were real. Despite its limitations, this study offers valuable insights into what creates a positive learning experience in a university course incorporating the FC approach and how this experience can be supported by both the teacher's personal actions and the institutional training.

\section{Acknowledgments and funding}

We are deeply grateful to all the teachers and students who participated in this study. This study was supported by a grant from the Finnish Ministry of Education and Culture DigiPeda Flipped Learning project [Grant no. OKM/199/523/2016].

\section{References}

Abeysekera, L., \& Dawson, P. (2015). Motivation and cognitive load in the flipped classroom: Definition, rationale and a call for research. Higher Education Research \& Development, 34(1), 1-14.

Alexander, B., Ashford-Rowe, K., Barajas-Murph, N., Dobbin, G., Knott, J., McCormack, M., ... \& Weber, N. (2019). EDUCAUSE Horizon report 2019 higher education edition (pp. 3-41). Louisville, CO: EDUCAUSE.

Baert, H., De Rick, K., \& Van Valckenborgh, K. (2006). Towards the conceptualisation of learning climate. Adult Education: New Routes in a New Landscape, 87-111.

Barr, R. B., \& Tagg, J. (1995). From teaching to learning - A new paradigm for undergraduate education. Change: The Magazine of Higher Learning, 27(6), 12-26.

Bergmann, J., \& Sams, A. (2012). Flip your classroom: Reach every student in every class every day. Eugene, OR: International Society for Technology in Education.

Bingham, C. (2011). Two Educational Ideas for 2011 and Beyond. Studies in Philosophy and Education, 30(5), 513-519.

Bishop, J. L., \& Verleger, M. A. (2013). The flipped classroom: A survey of the research. In ASEE National Conference Proceedings, 30(9), 1-18.

Boelens, R., De Wever, B., \& Voet, M. (2017). Four key challenges to the design of blended learning: A systematic literature review. Educational Research Review, 22, $1-18$.

Chen, J. L. (2011). The effects of education compatibility and technological expectancy on e-learning acceptance. Computers \& Education, 57(2), 1501-1511.

Creswell, J. W., \& Plano Clark, V. L. (2018). Designing and conducting mixed methods research (3rd ed.). Thousand Oaks, CA: SAGE Publications. 
Creswell, J. W., \& Poth, C. N. (2018). Qualitative inquiry and research design: Choosing among five approaches (4th ed.). Thousand Oaks, CA: SAGE Publications.

Critz, C. M., \& Knight, D. (2013). Using the flipped classroom in graduate nursing education. Nurse Educator, 38(5), 210-213.

Crouch, C. H., \& Mazur, E. (2001). Peer instruction: Ten years of experience and results. American Journal of Physics, 69(9), 970-977.

Cruz e Costa J., Ojala T., \& Korhonen J. (2008, April). Mobile lecture interaction: Making technology and learning click. Paper presented at the IADIS International Conference Mobile Learning 2008, Lisbon, Portugal.

Dane, J. (2016). The effective teaching and learning spatial framework: An evaluation tool. In W. Imms, B. Cleveland, \& K. Fisher (Eds.), Evaluating learning environments (pp. 211-228). Rotterdam, the Netherlands: Sense Publishers.

Dillenbourg, P. (1999). What do you mean by collaborative learning? In P. Dillenbourg (Ed.), Collaborative learning: Cognitive and computational approaches (pp. 1-19). Oxford, UK: Elsevier.

Entwistle, N., McCune, V., \& Hounsell, J. (2002). Approaches to studying and perceptions of university teaching-learning environments: Concepts, measures, and preliminary findings (Enhancing teaching-learning environments in undergraduate courses occasional report 1). Edinburgh, UK: ETL Project.

Field, A. (2018). Discovering statistics using IBM SPSS statistics (5th ed.). London, UK: SAGE Publications Ltd.

Forsey, M., Low, M., \& Glance, D. (2013). Flipping the sociology class: Towards a practice of online pedagogy. Journal of Sociology, 49(4), 471-485.

Freeman, A., Adams Becker, S., Cummins, M., Davis, A., \& Hall Giesinger, C. (2017). NMC/CoSN Horizon report: 2017 K-12 edition. Austin, TX: The New Media Consortium.

Harasim, L. (1996). Online education. In T. Harrison \& T. Stephen (Eds.), Computer networking and scholarly communication in the twenty-first-century university, (pp. 203-214). New York, NY: State University of New York Press.

Hung, W., Jonassen, D. H., \& Liu, R. (2008). Problem-based learning. Handbook of Research on Educational Communications and Technology, 3(1), 485-506.

Ifenthaler, D. (2010). Learning and instruction in the digital age. In J. M. Spector, D. Ifenthaler, P. Isaías, Kinshuk, \& D. G. Sampson (Eds.), Learning and instruction in the digital age: Making a difference through cognitive approaches, technology-facilitated collaboration and assessment, and personalized communications (pp. 3-10). New York, NY: Springer.

Imms, W., Cleveland, B., \& Fisher, K. (2016). Pursuing that elusive evidence about what works in learning environment design. In W. Imms, B. Cleveland, \& K. Fisher (Eds.), Evaluating learning environments (pp. 1-17). Rotterdam, the Netherlands: Sense Publishers.

James, A. J., Chin, C. K., \& Williams, B. R. (2014). Using the flipped classroom to improve student engagement and to prepare graduates to meet maritime industry requirements: A focus on maritime education. WMU Journal of Maritime Affairs, 13(2), 331-343.

Johnson, D. W., Johnson, R. T., \& Smith, K. (2007). The state of cooperative learning in postsecondary and professional settings. Educational Psychology Review, 19(1), 1529.

Kim, M. K., Kim, S. M., Khera, O., \& Getman, J. (2014). The experience of three flipped classrooms in an urban university: An exploration of design principles. The Internet and Higher Education, 22, 37-50. 
Kirk, R. E. (1996). Practical significance: A concept whose time has come. Educational and Psychological Measurement, 56(5), 746-759.

Kirschner, P. A., Sweller, J., \& Clark, R. E. (2006). Why minimal guidance during instruction does not work: An analysis of the failure of constructivist, discovery, problem-based, experiential, and inquiry-based teaching. Educational Psychologist, 41(2), 75-86.

Kozhevnikov, M., Evans, C., \& Kosslyn, S. M. (2014). Cognitive style as environmentally sensitive individual differences in cognition: A modern synthesis and applications in education, business, and management. Psychological Science in the Public Interest, 15(1), 3-33.

Krathwohl, D. R. (2002). A revision of Bloom's taxonomy: An overview. Theory into Practice, 41(4), 212-218.

Lasry, N., Dugdale, M., \& Charles, E. (2014). Just in time to flip your classroom. The Physics Teacher, 52(1), 34-37.

Limo'n, M. (2001). On the cognitive conflict as an instructional strategy for conceptual change: A critical appraisal. Learning and Instruction, 11(4-5), 357-380.

Loyens, M. M., \& Rikers, M. J. P. (2011). Instruction based on inquiry. In R. E. Mayer, P. A. Alexander (Eds.), Handbook of research on learning and instruction (pp. 361-381). New York, NY: Routledge.

Manninen, J., Burman, A., Koivunen, A., Kuittinen, E., Luukannel, S., Passi, S., \& Särkkä, H. (2007). Environments supporting learning: Introduction to learning-environmentthinking. Helsinki, Finland: Finnish National Broad of Education.

Mason, G., Shuman, T., \& Cook, K. (2013). Comparing the effectiveness of an inverted classroom to a traditional classroom in an upper-division engineering course. IEEE Transactions on Education, 56(4), 430-435.

McHaney, R. (2011). The new digital shoreline. How web 2.0 and millennials are revolutionizing higher education. Sterling, VA: Stylus Publishing.

McNally, B., Chipperfield, J., Dorsett, P., Del Fabbro, L., Frommolt, V., Goetz, S., ... \& Rung, A. (2017). Flipped classroom experiences: Student preferences and flip strategy in a higher education context. Higher Education, 73(2), 281-298.

Millis, B. J. (2010). Why faculty should adopt cooperative learning approaches. In B. J. Millis (Ed.), Cooperative learning in higher education: Across the disciplines, across the academy (pp. 1-9). Sterling, VA: Stylus Publishing.

Mishra, P., \& Koehler, M. J. (2006). Technological pedagogical content knowledge: A framework for teacher knowledge. Teachers College Record, 108(6), 1017-1054.

Mishra, P., Koehler, M. J., \& Henriksen, D. (2010). The 7 transdisciplinary habits of mind: Extending the TPACK framework towards 21st century learning. Educational Technology, 51(2), 22-28.

Missildine, K., Fountain, R., Summers, L., \& Gosselin, K. (2013). Flipping the classroom to improve student performance and satisfaction. Journal of Nursing Education, 52(10), 597-599.

Murphy, R., \& Sharma, N. (2010). What don't we know about interactive lectures? Seminar.net - International Journal of Media, Technology \& Life-Long Learning, 6(1), 111-120.

Nunnally, J. C. (1978). Psychometric theory (2nd ed.). New York, NY: McGraw-Hill.

O'Flaherty, J., Phillips, C., Karanicolas, S., Snelling, C., \& Winning, T. (2015). The use of flipped classrooms in higher education: A scoping review. Internet and Higher Education, 25, 85-95.

Oliver, G. (2016). Developing new learning environments: Co-constructing innovation in education practice. In W. Imms, B. Cleveland, \& K. Fisher (Eds.), Evaluating 
learning environments (pp. 107-116). Rotterdam, the Netherlands: Sense Publishers.

Ossiannilsson, E. (2018). Promoting active and meaningful learning for digital learners. In J. Keengwe (Ed.), Handbook of research on mobile technology, constructivism, and meaningful learning (pp. 294-315). Hershey, PA: IGI Global.

Poitras, E. G., \& Lajoie, S. P. (2013). A domain-specific account of self-regulated learning: The cognitive and metacognitive activities involved in learning through historical inquiry. Metacognition and Learning, 8(3), 213-234.

Prober, C. G., \& Khan, S. (2013). Medical education reimagined: A call to action. Academic Medicine, 88(10), 1407-1410.

Puranen, T., Helfenstein, S., \& Lappalainen, V. (2009). In situ - Technical description and preliminary evaluation of a TCP/IP connection-based teaching and learning communication system. Paper presented at eLAC 2009 - Conference.

Richards, G. (2019). Human evolution: An introduction for the behavioural sciences. New York, NY: Routledge.

Scager, K., Boonstra, J., Peeters, T., Vulperhorst, J., \& Wiegant, F. (2016). Collaborative learning in higher education: Evoking positive interdependence. CBE - Life Sciences Education, 15(4), ar69.

Sointu, E., Valtonen, T., Hirsto, L., Kankaanpää, J., Saarelainen, M., Mäkitalo, K., Smits, A., \& Manninen, J. (2019). Teachers as users of ICT from the student perspective in higher education flipped classroom classes. Seminar.net - International Journal of Media, Technology \& Life-Long Learning, 15(1), 1-15.

Strayer, J. (2012). How learning in an inverted classroom influences cooperation, innovation and task orientation. Learning Environments Research, 15, 171-193.

Talbert, R. (2017). Flipped learning: A guide for higher education faculty. Sterling, VA: Stylus Publishing.

Thornburg, D. (2013). From the campfire to the holodeck: Creating engaging and powerful 21st century learning environments. San Francisco, CA: Jossey-Bass, a Wiley brand.

Tuomi, J., \& Sarajärvi, A. (2018). Laadullinen tutkimus ja sisällönanalyysi [Qualitative research and content analysis, renewed ed.]. Helsinki, Finland: Tammi Publishers.

Tusa, N., Sointu, E., Kastarinen, H., Valtonen, T., Kaasinen, A., Hirsto, L., ... \& Mäntyselkä, P. (2018). Medical certificate education: Controlled study between lectures and flipped classroom. BMC Medical Education, 18(1), 243.

Valtonen, T., Havu-Nuutinen, S., Dillon, P., \& Vesisenaho, M. (2011). Facilitating collaboration in lecture-based learning through shared notes using wireless technologies. Journal of Computer Assisted Learning, 27(6), 575-586.

Valtonen, T., Sointu, E., Kukkonen, J., Kontkanen, S., Lambert, M. C., \& Mäkitalo-Siegl, K. (2017). TPACK updated to measure pre-service teachers' twenty-first century skills. Australasian Journal of Educational Technology, 33(3).

Voogt, J., \& Pareja Roblin, N. (2012). A comparative analysis of international frameworks for 21st century competences: Implications for national curriculum policies. Journal of Curriculum Studies, 44(3), 299-321.

Wang, Q. (2008). A generic model for guiding the integration of ICT into teaching and learning. Innovations in Education and Teaching International, 45(4), 411-419.

Wang, L., MacCann, C., Zhuang, X., Liu, O. L., \& Roberts, R. D. (2009). Assessing teamwork and collaboration in high school students: A multimethod approach. Canadian Journal of School Psychology, 24(2), 108-124.

West, D., \& Thompson, S. (2015). Mobile knowledge: Driving a paradigm shift. Journal of Applied Research in Higher Education, 7(1), 43-54. 
Yeung, K., \& O'Malley, P. (2014). Making 'the flip'work: Barriers to and implementation strategies for introducing flipped teaching methods into traditional higher education courses. New Directions in the Teaching of Physical Sciences, 10(1), 59-63.

\title{
Biographies
}

\begin{abstract}
Mareena Hyypiä
Mareena Hyypiä (M.A. Ed.) is a project researcher in the School of Educational Sciences and Psychology and the School of Applied Educational Science and Teacher Education at the University of Eastern Finland (UEF). She has previously worked on projects that focused on developing innovative pedagogies for digital fabrication and making technologies in STEAM subjects. She also has experience in flipped classroom in higher education, the digital readiness of higher education staff, and teacher training in using digital technologies in digital learning environments. Mareena is a trained classroom teacher.
\end{abstract}

\section{Erkko Sointu}

Erkko Sointu (PhD, Education) is a tenure-track assistant professor of learning and novel teaching method development in the School of Educational Sciences and Psychology at the UEF. His research interests lie in the utilization and students' perceptions of flipped classroom/learning (FC/L), technology in education, and strength-based approaches in basic education. He has been responsible for large-scale training in $\mathrm{FC} / \mathrm{L}$ for higher education teachers at UEF and also at other universities in Finland and internationally. He is also a trained teacher with experience in both comprehensive and higher education.

\section{Laura Hirsto}

Laura Hirsto (PhD, Educational psychology) is a research director and had been appointed to a professorship in the School of Applied Educational Science and Teacher Education at the UEF, and she is a senior lecturer in university pedagogy at the Higher Education Development Center at the University of Helsinki. Her research interests lie in the studying, learning and motivational processes of higher education students, teacher training, and the research-based development of teaching and learning environments (including $\mathrm{FC} / \mathrm{L}$ approaches) in various contexts. She is also a trained teacher with experience in both comprehensive and higher education.

\section{Teemu Valtonen}

Teemu Valtonen (PhD, Education) is a tenure-track associate professor in the School of Applied Educational Science and Teacher Education at the UEF. His research interests lie in the use of information and communication technology (ICT) in education, with a particular focus on (pre-service) teachers' skills and readiness to use ICT in education. In addition, his current research focuses on the integration of the flipped classroom model into higher education teaching practices. 